\title{
SEAWATER
}

\section{MAGAN MAGAN}

She presses her hand on his face, pushes his head towards her mouth, until the veins on his head scream of not wanting. She leans in and whispers this is where I have come to yell at God for three years.

When I walk in

I can see the sweat drip from her nose as though it is a leaking tap.

And with a wanting as hot as the sun he looks at me naked. I turn around and walk out.

Then with a shock as sweet as living, I find myself in the sea, under the waterlogged sky, drowning, terribly, hoping the drifting wood speaks out.

Inna lillahi wa inna ilayhi rajiun 